\section{New NSF program connects researchers, entrepreneurs}

\author{
www.nsf.gov/i-corps
}

$\mathbf{T}$ he National Science Foundation (NSF) debuted a new program last fall aimed at increasing the impact of NSF-funded basic research. Made possible through a public-private partnership, the NSF Innovation Corps, or I-Corps, will enable researchers to assess the commercial potential of new technologies or products based on their research over the next few years.

I-Corps provides a unique opportunity for materials researchers to learn entrepreneurial skills and explore potential applications of their work, said Mary Galvin, a program director for the Division of Materials Research. Whether it be in electronics, clean energy, biomaterials, or other needs, she said, the materials community has a lot of potential for commercializing its discoveries.

NSF primarily funds basic research, but advancing the health, prosperity, and welfare of the country is a critical component of its mission. I-Corps builds on NSF's basic research investments by providing $\$ 50,000$ in financial support and mentoring support for researchers as they explore the market viability of a product or technology. This exploratory phase is traditionally challenging for researchers because funding is difficult to secure before a technology's usefulness is demonstrated. Additionally, many researchers lack experience with business plans, licensing technology, and other entrepreneurial skills.

The mentorship element is critical to the I-Corps effort according to Errol Arkilic, program director for I-Corps. "Sometimes the skill set of the teams that do the basic research is different than the skill set required to refine those basic research properties into something that is commercially meaningful." The gap between basic research and commercial readiness is widening, he said. I-Corps aims to close this gap by helping researchers learn entrepreneurial skills and develop ideas to the point where they can attract outside funding.

One of the features that most distinguishes the I-Corps effort among NSF's portfolio of programs, said Galvin, is that it teaches professors, postdoctoral scholars, and graduate students what it takes to be entrepreneurs. All I-Corps awardees participate in a curriculum that includes a kick-off workshop, web-based lectures, and other learning opportunities. By bringing together research and entrepreneurial experts, NSF is creating a class of materials scientists that is educated in entrepreneurship as well as basic research, said Galvin.

I-Corps awards are made to teams consisting of a principal investigator who has an active or recently active NSF award, a postdoctoral or graduate student entrepreneurial lead, and a private sector mentor who has experience moving a similar type of technology, product, or process from an academic laboratory into the private sector. I-Corps mentors serve as thirdparty resources - they can be from the specific I-Corps mentor network or recommended by a proposing institution.

In October 2011, NSF announced the first round of awardees. The Directorate for Mathematical and Physical Sciences was well-represented among the 21 awards, said Arkilic, with materials playing a key role in multiple projects. These projects include graphene, photocatalysts for water remediation, and silicon terahertz electronics. Applications for the current round are being accepted through March 15, 2012.

Reflecting on this first round, Arkilic said that the highest performing I-Corps teams came in with a specific vision for how their technology could be used. The vision may change over time, he said, but teams need to start with a specific application or it is difficult to identify and communicate with potential customers.

This sentiment was echoed by Galvin. "Think about narrowing the platform or idea to one or two potential applications," she advises materials researchers interested in submitting a proposal to I-Corps. Even if a platform has many potential applications, focus on only a couple or the project will become too defocused to succeed, she said.

The I-Corps effort is a partnership between NSF and two foundations, the Ewing Marion Kauffman Foundation and the Deshpande Foundation. Both have a long history of supporting innovation and an appreciation for the challenges related to bringing a new technology from an academic laboratory to a wider market, said Arkilic. "We are very proud to be working with the Kauffman Foundation and Deshpande Foundation in a public-private partnership for this purpose." The I-Corps program also has a 
national network of advisors and partnering institutions.

The Directorate for Engineering manages I-Corps, but interested researchers should first discuss proposal ideas with a topic-specific program officer such as Galvin. Potential applicants should then talk to an I-Corps program officer-only proposals with prior written authorization from an ICorps program officer are accepted.

Up to 100 I-Corps awards will be made annually, with submission deadlines of March 15, June 15, September 15, and December 15. More information on the I-Corps program can be accessed at www.nsf.gov/i-corps.

Kendra Redmond
NSF announces new workplace flexibility policies www.nsf.gov/career-life-balance

$\mathbf{L}$ ast fall, Subra Suresh, director of the National Science Foundation, announced the "NSF Career-Life Balance Initiative," a 10-year plan to provide greater work-related flexibility to women and men in research careers. Among the best practices that NSF will expand Foundation-wide are ones that will allow researchers to delay or suspend their grants for up to one year in order to care for a newborn or newly adopted child or fulfill other family obligations. This initiative is designed to maximize current
NSF policy to facilitate scientists' reentry into their professions with minimal loss of momentum.

"Too many young women scientists and engineers get sidetracked or drop their promising careers because they find it too difficult to balance the needs of those careers and the needs of their families," said Suresh. "This new initiative aims to change that, so that the country can benefit from the full range and diversity of its talent."

Women currently earn $41 \%$ of $\mathrm{PhD}$ degrees in the fields of science, technology, engineering, and math (STEM), but make up only $28 \%$ of tenure-track faculty in those fields. According to NSF, reducing the rate in which women leave their STEM careers is especially important in the quest for gender equality because women in STEM jobs earn 33\% more than those in non-STEM occupations and the wage gap between women and men in STEM jobs is smaller than in other fields.

NSF is also calling upon universities and research institutes to adopt similar policies for their employees and grantees.
Directions in the Philippines for emerging science research set www.pcierd.dost.gov.ph

$\mathbf{R}$ esearchers in the Philippines can now program their research activities in emerging science with the setting up of the sector's research and development roadmaps.

Led by the Department of Science and Technology's Philippine Council for Industry, Energy and Emerging Technology Research and Development (DOSTPCIEERD) in workshops held last October, the crafting of the R\&D roadmaps involved stakeholders in the fields of genomics and nanotechnology.

"One important thing that you should consider in crafting the roadmaps is the final outcome of the research activity," Sec. Mario Montejo advised the stake- holders. "In the end, the final product that comes from research should uplift the lives of the Filipino people."

In nanotechnology, research activities will center on addressing the top 10 problems of the world in the next 50 years, including energy, water, food, environment, and poverty, among others. In the field of information communications and technology and semiconductors, nanotechnology research will be geared toward building core facilities for nanometrology, solar-cell testing, and failure analysis. Also set in the pipeline are nanomaterials sample preparation, chemical analysis and imaging, advanced materials, and high-resolution characterization.
Nanotechnology studies with energy applications will focus on device structures, bulk heterojunction-type solar cells, water-splitting photovoltaic system, and hydrogen fuel cells.

The stakeholders in this field also laid out plans to develop human resources, linkages, and marketing schemes of potential technologies to the industry.

In the field of health genomics, R\&D will focus more on the development of diagnostic kits for commonly encountered diseases. Also set in the pipeline are molecular marker studiers, DNA fingerprinting, sustainable drug discovery, and bioenergy production.

Framelia V. Anonas S\&T Media Service

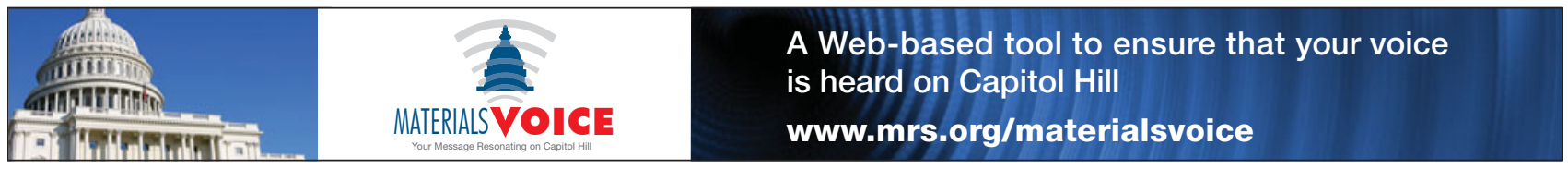

